\title{
Discursos produzidos por colonos do sul do país sobre a matemática e a escola de seu tempo
}

\author{
Fernanda Wanderer \\ Universidade do Vale do Rio dos Sinos, Centro de Ciências Humanas
}

\section{Gelsa Knijnik}

Universidade do Vale do Rio dos Sinos, Programa de Pós-Graduação em Educação

\section{Introdução}

Este trabalho apresenta resultados parciais de uma investigação que teve como propósito analisar discursos sobre a escola e a matemática escolar de um grupo de colonos, descendentes de alemães e evangélicos-luteranos, que freqüentavam uma escola rural do município de Estrela (RS) quando da efetivação dos decretos que instituíram a Campanha de Nacionalização - uma das medidas do Estado Novo (1937-1945), implementado no Brasil por Getúlio Vargas. A escolha desse período foi considerada por ter sido um momento importante de transformações políticas, econômicas e sociais, endereçando novas políticas educacionais para os descendentes de alemães do sul do país. Além disso, ao estudar uma comunidade rural, seria possível problematizar, especificamente no contexto escolar e da educação matemática, as enunciações produzidas sobre os sujeitos rurais, tanto no período enfocado como nos dias atuais, constituindoos com as marcas do atraso.

A sustentação teórica do artigo (assim como das demais partes da investigação) encontra-se no campo da etnomatemática - constituído mediante os entrecruzamentos das teorizações pós-estruturalistas, em especial o pensamento de Michel Foucault, e das idéias formuladas por Ludwig Wittgenstein (2004) em sua obra Investigações filosóficas. O material de pesquisa examinado consistiu em narrativas produzidas por um grupo de sete colonos que estudaram naquela escola no período enfocado ${ }^{1}$ e em um texto elaborado por "seu" Herbert, um dos participantes da pesquisa (sem que houvesse solicitação para isso), no qual narrou suas experiências de menino estudante, explicitando elementos da matemática escolar praticada naquela escola rural. As narrativas foram geradas mediante entrevistas individuais, realizadas em suas casas, em duas sessões, cada uma de aproximadamente duas horas.

Apoiando-nos nos aportes teóricos escolhidos, principalmente na discussão desenvolvida por Foucault sobre a noção de discurso, o material de pesquisa foi avaliado, buscando seguir o que diz Veiga-Neto

${ }^{1}$ Quando da realização das entrevistas, a idade dos participantes da pesquisa variava entre 75 e 79 anos. 
(2003) sobre a análise do discurso na perspectiva foucaultiana: "É preciso ler o que é dito simplesmente como um dictum, em sua simples positividade" (p. 117). Para o autor, não se trata de

\section{[...] organizar previamente os discursos que se quer analisar,} nem tentar identificar sua lógica interna e algum suposto conteúdo de verdade que carregam, nem mesmo buscar neles uma essência original, remota, fundadora, tentando encontrar, nos não-ditos dos discursos sob análise, um jádito ancestral e oculto. (idem, p. 118)

Considerando esses entendimentos, ao selecionar, organizar e constituir as relações entre as enunciações que conformaram o material de pesquisa buscou-se submetê-las, conforme aponta Bujes (2002), a um "rigoroso escrutínio", que, nas palavras da autora, é realizado com o material de pesquisa para "confrontálo, voltar a ele muitas vezes; perguntar-me da possibilidade de estabelecer com/sobre ele novas relações e, quem sabe, alcançar nestes jogos outras formas de inteligibilidade" (p. 90).

Este artigo está organizado em quatro seções. Após esta introdução, na próxima seção serão discutidos os aportes teóricos que embasaram a investigação. Na terceira seção é explicitado o resultado do exercício analítico posto em ação por meio das ferramentas teóricas anteriormente discutidas. A última seção apresenta uma breve síntese das idéias apresentadas.

\section{Operando com Foucault e Wittgenstein na constituição do campo etnomatemático}

O campo etnomatemático emerge como uma perspectiva da educação matemática em meados da década de 1970, com os estudos de Ubiratan D’Ambrosio (Barton, 2004; D'Ambrosio, 1997, 2001; Knijnik, 2006a). Sendo referido como o autor mais influente na produção etnomatemática, D' Ambrosio expressa que essa perspectiva busca "entender o saber/ fazer matemático ao longo da história da humanidade, contextualizado em diferentes grupos de interesse, comunidades, povos e nações" (2001, p. 17). Assim, a literatura etnomatemática destaca a relevância do exame das matemáticas produzidas pelos mais diversos grupos sociais, especificamente suas formas de organizar, gerar e disseminar os conhecimentos (matemáticos) presentes em suas culturas.

Desde sua emergência, a etnomatemática vem-se constituindo num campo vasto e heterogêneo, impossibilitando a enunciação de generalizações no que diz respeito a seus aportes teórico-metodológicos, como mostram os trabalhos de Knijnik (2004a, 2006a), Frankenstein e Powell (1997), Monteiro (2004) e Conrado (2005). Mais recentemente, trabalhos como os de Knijnik (2006a, 2006b), Knijnik e Wanderer (2006a, 2006b) e Wanderer (2007) têm-se servido das teorizações pós-estruturalistas, principalmente a vertente associada ao pensamento de Foucault, e das formulações teóricas do segundo Wittgenstein para atribuir novos sentidos à etnomatemática. Assim, Knijnik (2006a) configura o campo etnomatemático afirmando que ele possibilita

\footnotetext{
[...] estudar os discursos eurocêntricos que instituem a matemática acadêmica e a matemática escolar; analisar os efeitos de verdade produzidos pelos discursos da matemática acadêmica e da matemática escolar; discutir questões da diferença na educação matemática, considerando a centralidade da cultura e das relações de poder que a instituem, problematizando a dicotomia entre "alta" cultura e "baixa" cultura na educação matemática. (p. 120)
}

Considerando a matemática acadêmica e a matemática escolar como discursos, no sentido foucaultiano, a etnomatemática, da forma como a temos compreendido, permite analisar seus vínculos com a produção das relações de poder-saber e com a constituição de regimes de verdade. Como expressa Foucault, "o que faz com que o poder se mantenha e que seja aceito é simplesmente que ele não pesa só como uma força que diz não, mas que ele de fato permeia, produz coisas, induz ao prazer, forma saber, produz discursos" (2003, p. 8). Dessa forma, na concepção foucaultiana, os discursos da matemática acadêmica e da escolar são estudados levando em 
conta as relações de poder-saber que ao mesmo tempo os produzem e são por eles produzidas.

Nesse registro teórico, os discursos das matemáticas acadêmica e escolar podem ser pensados como constituídos por (ao mesmo tempo em que constituem) uma "política geral da verdade" (Foucault, 2003), uma vez que alguns procedimentos e técnicas - praticados pela academia - são considerados os mecanismos (únicos e possíveis) capazes de gerar conhecimentos (como as maneiras "corretas" de demonstrar teoremas, utilizando axiomas e corolários ou, então, pela aplicação de fórmulas, seguindo-se "corretamente" todos os seus passos), em um processo de exclusão de outros saberes que, por não utilizarem as mesmas regras, são classificados como "não-matemáticos". Tal operação passa a ser realizada por alguns profissionais - cujas carreiras estão vinculadas à academia, como os matemáticos -, que se tornam capazes "de dizer o que funciona como verdadeiro" no campo da educação matemática. Assim, na ordem discursiva que engendra a matemática acadêmica e a matemática escolar, são produzidas, sobre essa área do conhecimento, "verdades" que atuam na geração de concepções sobre como deve ser um professor de matemática, quem são os "bons e maus" alunos ou como esse campo do saber atua na sociedade, demarcando diferenças e construindo identidades.

As idéias de Ludwig Wittgenstein em Investigações filosóficas (publicado em 1953) podem ser produtivas para prosseguir a discussão de questões do campo etnomatemático. Ao questionar suas concepções anteriores, ${ }^{2}$ o filósofo destaca a relevância do papel da linguagem na constituição do mundo, incitando problematizações que possibilitam sustentar filosoficamente a etnomatemática (Knijnik, 2006b). Se Wittgenstein, na segunda fase de sua trajetória intelec-

${ }^{2}$ A trajetória intelectual de Wittgenstein pode ser dividida em duas fases: a primeira, cuja obra principal é o livro Tractatus Lógico-Philosophicus (publicado em 1921), no qual discute a incapacidade da linguagem em lidar com a metafísica da realidade; e a segunda, associada à obra Investigações filosóficas. tual, nega a existência de uma linguagem universal, tal posição leva a questionar a noção de uma linguagem matemática universal, o que aponta para a produtividade do pensamento do filósofo para atribuir novos sentidos para os fundamentos da etnomatemática.

Mesmo que em suas teorizações D'Ambrosio não tenha explicitado vínculos com o pensamento de Wittgenstein, as idéias do educador brasileiro - ao reconhecer diferentes e múltiplas matemáticas, colocando sob suspeição a existência de uma linguagem matemática universal - podem ser pensadas com base na filosofia da maturidade wittgensteiniana. Recentemente, estudos do campo da etnomatemática - como os desenvolvidos por Villela (2006) e os anteriormente citados de Knijnik (2006b), Knijnik e Wanderer (2006a, 2006b) e Wanderer (2007) - têm utilizado as idéias do segundo Wittgenstein para questionar a noção de uma linguagem matemática universal, possibilitando, com isso, que sejam consideradas diferentes matemáticas, como indicado pelo pensamento etnomatemático.

Wittgenstein, na segunda fase de sua trajetória, concebe a linguagem não mais com as marcas da universalidade, perfeição e ordem, como se preexistisse às ações humanas. Em Investigações filosóficas, o autor afirma: "Não aspiramos a um ideal: como se nossas proposições habituais e vagas não tivessem ainda um sentido irrepreensível, e uma linguagem perfeita estivesse ainda por ser construída por nós" (2004, p. 68). Assim como contesta a existência de uma linguagem universal, o filósofo problematiza a noção de uma racionalidade total e a priori, apostando na constituição de diversos critérios de racionalidade. "Talvez um dos aspectos mais importantes dessa filosofia [do segundo Wittgenstein] seja possibilitar, a partir do caráter relacional dos usos nos seus diversos contextos e situações, um novo modelo de racionalidade" (Condé, 2004a, p. 49).

Wittgenstein, nessa segunda fase, repudia a noção de um fundamento ontológico para a linguagem; esta assume um caráter contingente e particular, adquirindo sentido mediante seus diversos usos. "O significado de uma palavra é seu uso na linguagem”, explicita o filósofo (2004, p. 38). Dessa forma, sendo a significação de uma palavra gerada pelo seu uso, a possibilidade de 
essências ou garantias fixas para a linguagem é posta sob suspeição, levando-nos a questionar também a existência de uma linguagem matemática única e com significados fixos.

Pode-se vincular essas idéias wittgensteinianas às discussões propostas pela etnomatemática, ao colocar sob suspeição a noção de uma linguagem matemática universal que seria "desdobrada", "aplicada" em múltiplas práticas produzidas pelos diferentes grupos culturais. Em vez disso, o pensamento do segundo Wittgenstein é produtivo para fazer pensar em diferentes matemáticas (associadas a diferentes formas de vida - como as de grupos de crianças, jovens, adultos, trabalhadores de setores específicos, acadêmicos, estudantes etc.), que ganham sentido em seus usos.

Intérpretes de Wittgenstein, como Condé (1998, 2004a, 2004b) e Moreno (2000), destacam que a noção de uso se torna central para a compreensão de linguagem desenvolvida na obra de maturidade do filósofo. Para Condé, "situações diferentes podem gerar significações diferentes para a mesma palavra" (2004a, p. 48). Dessa forma, seguindo seus argumentos, podese dizer que é o contexto que constitui a referência para entender a significação das linguagens (entre elas, as linguagens matemáticas) presentes nas atividades produzidas pelos diversos grupos culturais.

Ao destacar a geração de muitas linguagens que ganham sentidos mediante seus usos, Wittgenstein (2004) enfatiza a noção de jogos de linguagem:

E poder-se-ia chamar também de jogos de linguagem os processos de denominação das pedras e de repetição da palavra pronunciada. Pense em certo uso que se faz das palavras em brincadeiras de roda. Chamarei de "jogo de linguagem" também a totalidade formada pela linguagem e pelas atividades com as quais ela vem entrelaçada. (p. 19)

Para o filósofo, poder-se-ia compreender os jogos de linguagem como a "totalidade formada pela linguagem e pelas atividades com as quais ela vem entrelaçada". Assim, processos como descrever objetos, relatar acontecimentos, construir hipóteses e analisá-las, contar histórias e resolver tarefas de cálculo aplicado, entre outros, Wittgenstein denomina jogos de linguagem. Seguindo esse entendimento, é possível pensar que explicitar as matemáticas geradas em atividades específicas também é um processo que pode ser significado como jogos de linguagem no sentido atribuído pelo filósofo. Moreno (2000) destaca que, para a compreensão do significado, não se trata de buscar por uma determinação lógica e definitiva capaz de apreendê-lo "de uma vez por todas", mas interessa analisar os critérios "fornecidos pelo uso que fazemos da linguagem nos mais diversos jogos, isto é, nas diferentes formas de vida" (p. 56). Pode-se dizer que a noção de forma de vida passa a ser compreendida, na obra de maturidade de Wittgenstein, como vinculada à produção dos jogos de linguagem.

"A forma de vida é o ancoradouro último da linguagem”, destaca Condé (1998, p. 104), afirmando que a significação das palavras, dos gestos e, poder-se-ia acrescentar, das linguagens matemáticas e dos critérios de racionalidade presentes nelas é constituída no contexto de uma dada forma de vida. Assim, as matemáticas produzidas em diversas formas de vida constituemse em diferentes jogos de linguagem. Condé (2004a, p. 52) expressa essa relação afirmando que, sendo a matemática um produto cultural, pode ser significada como um jogo de linguagem. Assim, a matemática acadêmica, a matemática escolar, as matemáticas camponesas, as matemáticas indígenas, em suma, as matemáticas geradas por grupos culturais específicos podem ser entendidas como jogos de linguagem associados a diferentes formas de vida, agregando critérios de racionalidade específicos. Porém, esses diferentes jogos não possuem uma essência invariável que os mantenha completamente incomunicáveis uns com os outros, tampouco uma propriedade comum, mas algumas analogias ou parentescos - o que Wittgenstein (2004) denomina semelhanças de família.

Glock (1998) afirma que se pode compreender a noção de semelhanças de família desenvolvida por Wittgenstein não como um fio único que perpasse todos os jogos de linguagem, mas como fios que se entrecruzam, como em uma corda, constituindo tais jogos. Para ele, 
Quando "olhamos e vemos" se todos os jogos possuem algo em comum, notamos que se unem, não por um único traço definidor comum, mas por uma complexa rede de semelhanças que se sobrepõem e se entrecruzam, do mesmo modo que os diferentes membros de uma família se parecem uns com os outros sob diferentes aspectos (compleição, feições, cor dos olhos etc.). (p. 324-325)

Condé (2004a), seguindo os argumentos de Wittgenstein, destaca que é na relação entre os jogos de linguagem e as semelhanças de família que se engendram os critérios de racionalidade. Para o autor, tais critérios "constituem-se não a partir de essências ou pontos estáticos e específicos, mas na dinâmica das complexas relações que articulamos a partir das semelhanças de família entre as muitas características dos jogos de linguagem" (p. 58).

Pelo exposto até aqui, pode-se afirmar que os argumentos do segundo Wittgenstein permitem que se compreendam as matemáticas como jogos de linguagem que possuem semelhanças entre si. Nas palavras de Condé: "o que existe são os diversos aspectos da linguagem que se expressam através dos jogos de linguagem que são múltiplos, variados e, principalmente, particulares" (1998, p. 124). Assim, para o autor, não há superconceitos que se pretendam universais e que possam servir como parâmetro para outros. Distintos jogos assemelham-se uns aos outros, possuem analogias, semelhanças que os perpassam e que permitem o engendramento de diferentes critérios de racionalidade.

É importante destacar, também, como a compreensão do papel atribuído à linguagem para o segundo Wittgenstein e para Foucault apresenta pontos de convergência, como demonstra, com propriedade, Veiga-Neto (2003). O autor explicita que

\footnotetext{
[...] mesmo sem ter jamais feito alguma referência explícita a Ludwig Wittgenstein - pelo menos segundo os registros até agora disponíveis aos especialistas - Foucault partilha muito de perto da grande maioria das descobertas que o filósofo austríaco havia feito no campo da linguagem. (p. 108)
}

Esses entendimentos convergentes apontam para a consistência da operação analítica posta em ação no presente estudo, ao considerar como campo teórico a etnomatemática em seus entrecruzamentos com as posições pós-estruturalistas foucaultianas e o pensamento do segundo Wittgenstein.

\section{Analisando o material de pesquisa}

A estratégia analítica posta em ação para operar com o material de pesquisa, em consonância com os aportes teóricos do estudo, orientou-se pela análise foucaultiana do discurso. Para o filósofo, os discursos, considerados um conjunto de enunciados, são compreendidos como "práticas que formam sistematicamente os objetos de que falam", afastando-se do entendimento de que seriam "um puro e simples entrecruzamento de coisas e palavras: trama obscura das coisas, cadeia manifesta, visível e colorida das palavras" (Foucault, 2002, p. 56). Ele destaca ainda que a análise dos enunciados se refere àquilo que foi dito, seja de forma escrita ou oral, não se tratando, então, de questionar aquilo que ocultam, "mas, ao contrário, de que modo existem, o que significa para elas [coisas ditas] o fato de se terem manifestado, de terem deixado rastros e, talvez, de permanecerem para uma reutilização eventual; o que é para elas o fato de terem aparecido - e nenhuma outra em seu lugar" (idem, p. 126).

Essas teorizações foram tomadas como ferramentas para examinar o material de pesquisa, e esse escrutínio fez emergir a idéia de que a matemática escolar foi sendo constituída como um conjunto de jogos de linguagem marcado pela escrita, pelo formalismo e sustentado por dispositivos didáticos como a tabuada. De acordo com um dos entrevistados, na escola, os cálculos matemáticos "tinham que ser feitos na pedra. Depois, quando a gente ficou, assim, nos últimos anos, no terceiro e quarto ano, daí, já tinha que escrever dentro do caderno, né". ${ }^{3}$ Além de posicionar a matemática escolar como um saber marcado pela

\footnotetext{
${ }^{3}$ Para diferenciar as citações dos excertos extraídos das
} narrativas orais analisadas, esses estão grifados na formatação em itálico. Já os excertos do texto elaborado por seu Herbert estão inseridos em quadros. 
escrita, ele destacou também a necessidade de seguir as regras, fórmulas e de "mostrar como se faz". Em suas palavras: "tinha que fazer a conta. Se tu sabe na cabeça, não podia botar lá só o valor, tinha que fazer a conta, ele [professor] queria ver".

Durante a entrevista, foi solicitado a ele que explicasse como resolvia alguns dos problemas de matemática presentes na cartilha utilizada na escola. ${ }^{4}$ Eis um dos exercícios: "A nossa escola tem três classes. A primeira classe tem 34 alunos, a segunda tem 37 e a terceira 28". Ele rapidamente falou: "99". Quando questionado sobre como encontrou esse valor oralmente, disse: "34 e 37 dá 71 e mais 28 falta um pra 100”. E completou: "Eu fiz a conta certa, né, mas o professor já me castigava porque eu não mostrei como é que eu fiz. Ele queria que a gente mostrasse como é que vocêfez, né. Aí, não podia dizer 'não sei'. Ele queria saber onde tu tomaste nota".

Os termos presentes nos excertos - "tinha que fazer a conta"; "ele queria ver"; "ele queria que a gente mostrasse como é que você fez"; "ele queria saber onde tu tomaste nota" - remetem-nos à constituição da matemática escolar como um conjunto de jogos de linguagem marcado pela escrita e pelo formalismo, instituindo determinados critérios de racionalidade. Tais critérios estiveram presentes também no texto elaborado por um dos participantes da investigação, que integrou o material de pesquisa, como antes mencionado. Eis alguns excertos:

${ }^{4}$ As cartilhas utilizadas na escola investigada correspondem aos volumes 1 e 2 da obra Meu livro de contas, escrita por W. Nast e Leonhard Tochtrop. Segundo os autores, o $1^{\circ}$ volume endereçava-se ao $1^{\circ}$ ano primário; o $2^{\circ}$ volume, aos $2^{\circ}$ e $3^{\circ}$ anos; o $3^{\circ}$ volume, ao $4^{\circ}$ ano; e o $4^{\circ}$ volume, ao $5^{\circ}$ ano primário. Para Mauro (2005), o $1^{\circ}$ volume foi disponibilizado no ano letivo de 1933 , tornando-se completa a obra, tanto na edição em alemão quanto em português, em 1938. De acordo com os participantes deste estudo, apenas os volumes 1 e 2 , escritos em português, foram utilizados por eles na escola.

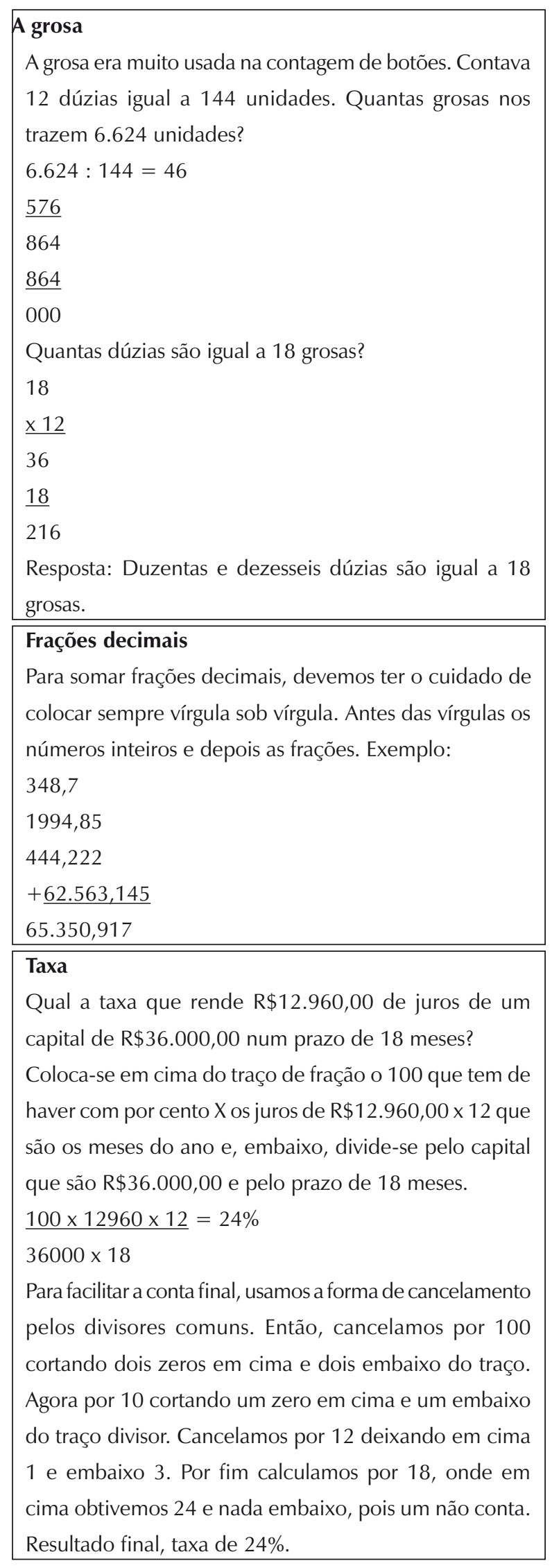


Seu Herbert, na parte final do material que elaborou, apresentou uma série de atividades que aprendera na escola, entre as quais as mencionadas anteriormente. Poder-se-ia dizer que ele, ao escrever sobre suas experiências, foi constituindo a linguagem da matemática escolar com as marcas da escrita, da abstração, do rigor, da "pureza" e do cumprimento de regras: as atividades seguiam uma sequiência determinada, composta por um título (conteúdo matemático), uma explicação detalhada, uma pergunta, um cálculo e, ao final, uma resposta completa. As operações matemáticas apresentadas foram efetuadas por meio dos algoritmos escritos, que se sustentam por uma racionalidade específica que exige o cumprimento de regras, como a colocação de "vírgula sob vírgula" para a adição de números decimais, por exemplo.

Além da relevância do cumprimento de cada etapa para que os exercícios estivessem corretos e "limpos", nas narrativas dos participantes da pesquisa evidencia-se a tabuada como fundamento para a realização das operações da matemática escolar, como mostram os excertos a seguir, extraídos das entrevistas realizadas:

A gente tinha que estudar de cor a tabuada. Tinha escrita no caderno e, daí, tinha que estudar. Daí, ele [professor] perguntava, por exemplo: 3 vezes 15 quanto é? Aí, tu tinha que saber, tinha que estudar isso. Não podia olhar lá dentro [do caderno].

Pra fazer contas, assim, eu era bem boa, porque eu sabia bem a tabuada. [...]. Mas isso era fácil de fazer pra quem conheceu bem a tabuada, esse que é o fundamento de fazer contas, porque hoje eu faço qualquer conta ligeiro, assim. Mas tinha que saber a tabuada, que é o fundamento, senão não vai, não faz contas. Eu sempre, já falei, quem sabe bem a tabuada, ele não se aperta nunca pra fazer conta. É o fundamento! Agora quem não sabia a tabuada fazia tudo errado.

Antes de estudar matemática, nós tinha que aprender a tabuada. O aluno do segundo ano já devia saber a tabuada de frente pra trás e de trás pra frente, do um até dez. Isso era sagrado. A primeira coisa, senão não podia fazer a matemática.
Essas formulações, ao enfatizar que "a gente tinha que estudar de cor a tabuada", significando-a como "fundamento da multiplicação", "fundamento de fazer contas", "a primeira coisa, senão não podia fazer a matemática”, constituem a matemática escolar como um corpo de conhecimentos hierarquizado e sustentado por pré-requisitos que possibilitam aos alunos "não se apertar[em] nunca pra fazer conta [s]". Assim, poder-se-ia dizer que o conjunto de jogos de linguagem que conforma a matemática escolar posta em ação naquela escola rural era constituído por regras que dizem da importância de decorar a tabuada e de efetuar as contas de maneira escrita, apresentando todas as etapas de sua realização.

O conjunto das regras presentes nos jogos de linguagem constitui o que Wittgenstein (2004) denomina gramática. Para o filósofo, pode-se compreender que a gramática, constituída por regras, possibilita entender o mundo e estabelecer o que tem ou não sentido, o que será tomado como certo ou errado. A gramática abrange proposições, gestos, práticas, enfim, todo o mecanismo que compõe os jogos de linguagem.

Além disso, Condé (2004a) enfatiza que a gramática não comporta uma essência, mas, como produto social, emerge nas relações da linguagem em uma dada prática social. “[...] as regras que constituem a gramática estão inseridas na prática social. Uma regra pode apenas constituir-se efetivamente como tal pela práxis social. A gramática é um produto social” (p. 89). Para o autor, na concepção de gramática desenvolvida por Wittgenstein, as regras são entendidas como invenção e criação, não como uma essência ou correspondência direta com o mundo. Porém, não são totalmente arbitrárias, pois mantêm sua coerência com o conjunto das outras regras, isto é, com a gramática.

Em outro estudo, Condé (1998, p. 124) afirma que as regras gramaticais incorporam as racionalidades que emergem em uma forma de vida. Assim, os argumentos desenvolvidos pelo segundo Wittgenstein sobre a gramática e os jogos de linguagem são produtivos para que se problematize o entendimento de uma razão universal, fundacionista e a priori que sustenta o pensamento moderno. Nas palavras de Condé (2004a): 
A gramática e as interações dos jogos de linguagem constituem as teias da razão. Em outros termos, perante a crise da racionalidade, no lugar da razão abstrata, centralizada e fundacionista que caracterizou o pensamento moderno, Wittgenstein "propõe" a gramática e os jogos de linguagem como uma racionalidade que se forja a partir das práticas sociais em uma forma de vida e que não mais se assenta em fundamentos últimos. (p. 29)

Seguindo as idéias do segundo Wittgenstein, ao examinar o material de pesquisa, pode-se observar, nas narrativas dos participantes deste trabalho, a geração de distintos jogos de linguagem. Se nessas narrativas a matemática escolar foi sendo constituída como um conjunto de jogos marcado pela escrita e pelo formalismo, as matemáticas geradas nas atividades cotidianas dos sujeitos entrevistados foram sendo produzidas por uma outra gramática que gerava outros critérios de racionalidade. Para Condé: “[...] naturalmente, formas de vida diversas estabelecem práticas diferenciadas, assim também, gramáticas diferentes e, conseqüentemente, inteligibilidades diferentes" (2004a, p. 110).

Um dos colonos entrevistados, ao relatar algumas de suas experiências como vendedor de carnes, destacou: "Naquela época, quando eu tinha matadouro, as carnes custavam um e vinte, um e trinta. Então, comprava dois quilos ou três quilos e duzentos gramas. Isso tudo era na cabeça". Para explicar como encontrava o valor a ser pago por clientes na compra de carnes, remeteu-se a uma situação em que o quilo custa $\mathrm{R} \$ 4,20$ e o comprador deseja dois quilos e duzentos gramas. Segundo ele, quando comercializava carnes em seu matadouro, realizava cálculos da seguinte maneira:

Dois quilos dá $\mathrm{R} \$ 8,40$. Eu faço primeiro a redonda, né, os $\mathrm{R} \$ 4,00$. Faço 2 vezes 4, porque é $\mathrm{R} \$ 4,20$. Faço primeiro o 4, 2 vezes 4 são 8. São R\$8,00. Daí, mais 2 vezes 2 são 4 , né. Isso tudo a gente tinha que fazer de cabeça. [...] E 200 gramas, então, é 2 vezes 42, né. A tabuada, isso era uma coisa que eu aprendi até dez, até dez, isso era o principal, né. Cem gramas então dá $\mathrm{R} \$ 0,42,100$ gramas, né, porque 10 vezes $\mathrm{R} \$ 0,40$ dá $\mathrm{R} \$ 4,00$ e os 2 , então, dá 4, 40 centavos, então, tem que fazer 2 vezes 42 .
E completou sua explicação dizendo:

Nos 100 gramas, tem que contar, né. Porque 100 gramas custam tanto, né. Se um quilo custa $R \$ 4,00$, então, 100 gramas custam $R \$ 0,40$, porque 10 vezes 4 são 40 . Assim eu sempre penso pra fazer a conta. Primeiro fazer a conta cheia, deixar os centavos fora. Vamos supor, $\mathrm{R} \$ 4,20$, faz primeiro de $R \$ 4,00$, ou de $R \$ 5,00$, ou de $R \$ 8,00$. Dez quilos custam tanto, dez quilos a $R \$ 8,00$ custam $R \$ 80,00$. Isso aí, depois, faz os 100 gramas.

Da mesma forma, outra colona entrevistada também mencionou práticas vinculadas à comercialização de carnes. Para explicar como procede para encontrar o valor total de uma compra de 40 quilos de carne, disse:

Agora não me lembro como é que vou te falar, mas... por exemplo, 40 quilos de carne a $\mathrm{R} \$ 4,00$. Quatro vezes 4 dá 16 , então, eu faço assim: 4 vezes 4 dá 16, daí, eu acrescento o zero, dá $\mathrm{R} \$ 160,00$. Como eu te disse, eu faço ele pequeno, né, pequenos números.

Esses excertos podem ser pensados como apresentando jogos de linguagem que possuem semelhanças entre si. Em tais jogos se fazem presentes algumas regras, como a decomposição, a estimativa e o arredondamento, que diferem daquelas presentes na gramática que engendra a matemática escolar. Essas regras também constituíram os jogos evidenciados em uma pesquisa desenvolvida por Knijnik (2004b) junto a um grupo de camponeses do Movimento Sem Terra.

Poder-se-ia afirmar que os colonos entrevistados faziam uso de operações matemáticas que consideram, num primeiro momento, as ordens de maior relevância para o encontro de seu valor final, da mesma forma que os participantes do estudo de Knijnik (2004b). Quando o primeiro entrevistado disse: "Faço primeiro a redonda", estava referindo-se à multiplicação da parte inteira dos números decimais, que, no seu caso, era mais importante para a obtenção do valor total a ser pago pelos compradores de carne. A estratégia 
utilizada pela segunda entrevistada, de "fazer primeiro os números pequenos", também se associa a esse raciocínio, uma vez que ela multiplicava, em primeiro lugar, as dezenas e apenas "acrescenta[va] os zeros" ao final, obtendo, assim, o resultado da operação.

Ao serem questionados sobre suas maneiras de realizar cálculos orais, eles afirmaram que não as aprenderam na escola. "Isso foi na vida prática. $\mathrm{Na}$ aula, eu não aprendi nada, na aula, só a tabuada que a gente aprendeu, só a tabuada", disse um deles. Na mesma direção expressou-se a outra entrevistada: "Isso eu aprendi depois... assim, fazendo as contas, né". Em suma, um dos resultados obtidos por meio do exercício analítico posto em ação aponta para a idéia de que os jogos de linguagem que constituíam a matemática escolar ignoravam a presença de algumas regras que se faziam presentes em outros jogos, como nos expressos anteriormente.

\section{Para concluir}

O exame do material de pesquisa - efetivado com o apoio das teorizações etnomatemáticas construídas com base nas formulações foucaultianas e nas idéias do segundo Wittgenstein - permite inferir que a matemática escolar praticada naquela escola rural, especificamente quando da efetivação dos decretos que instituíram a Campanha de Nacionalização, foi sendo constituída como um conjunto de jogos de linguagem marcado pela escrita e pelo formalismo, apoiado em fundamentos como a tabuada. Já as matemáticas geradas nas atividades cotidianas dos participantes do estudo podem ser significadas como conformando jogos de linguagem regidos por outra gramática, que utilizava regras como a oralidade, a decomposição, a estimativa e o arredondamento, constituindo critérios de racionalidade diferentes daqueles presentes no jogo que engendrava a matemática escolar.

Ao finalizar este artigo, é importante dizer que sua escrita e o desenvolvimento da pesquisa do qual é parte, ao colocar sob suspeição a noção de uma linguagem matemática universal que seria "aplicada" nas múltiplas práticas geradas pelos variados grupos, alargaram nosso entendimento de questões centrais do campo etnomatemático. Com isso, possibilitou compreender algumas das "verdades" que constituíam a matemática escolar de um tempo passado, cujos vestígios acabam por constituir a matemática escolar de hoje. Nesse processo, foi possível, ademais, atribuir novos sentidos para as verdades sobre a educação matemática que circulam entre nossos alunos do curso de pedagogia - futuros professores das séries iniciais do ensino fundamental -, que, assim como os participantes da pesquisa aqui discutida, são descendentes daqueles alemães que chegaram ao sul do país nos movimentos de colonização do século XIX, tendo sua história marcada pela cultura rural.

\section{Referências bibliográficas}

BARTON, Bill. Dando sentido à etnomatemática: etnomatemática fazendo sentido. In: RIBEIRO, José Pedro Machado; DOMITE, Maria do Carmo Santos; FERREIRA, Rogério (Orgs.). Etnomatemática: papel, valor e significado. São Paulo: Zouk, 2004. p. 39-74.

BUJES, Maria Isabel Edelweiss. Infância e maquinarias. Rio de Janeiro: DP\&A, 2002.

CONDÉ, Mauro Lúcio Leitão. Wittgenstein, linguagem e mundo. São Paulo: Annablume, 1998.

As teias da razão: Wittgenstein e a crise da racionalidade moderna. Belo Horizonte: Argvmentvm, 2004a.

Wittgenstein e a gramática da ciência. Revista Unimontes Científica, Montes Claros, v. 6, n. 1, jan./jun. 2004b.

CONRADO, Andréia Lunkes. A pesquisa brasileira em etnomatemática. Desenvolvimento, perspectivas, desafios. Dissertação (Mestrado em Educação) - Faculdade de Educação, Programa de Pós-Graduação em Educação, Universidade de São Paulo, São Paulo, 2005.

D’AMBROSIO, Ubiratan. Educação matemática. Da teoria à prática. Campinas: Papirus, 1997.

Etnomatemática: elo entre a tradição e a modernidade. Belo Horizonte: Autêntica, 2001.

FOUCAULT, Michel. Arqueologia do saber. Rio de Janeiro: Forense Universitária, 2002.

Microfísica do poder. Rio de Janeiro: Graal, 2003.

FRANKENSTEIN, Marilyn; POWELL, Arthur. Ethnomathematics: challenging eurocentrism in mathematics education. New York: SUNY Press, 1997. 
GLOCK, Hans-Johann. Dicionário Wittgenstein. Rio de Janeiro: Jorge Zahar, 1998.

KNIJNIK, Gelsa. Itinerários da etnomatemática: questões e desafios sobre o cultural, o social e o político na educação matemática. In: KNIJNIK, Gelsa; WANDERER, Fernanda; OLIVEIRA, Cláudio Jose. Etnomatemática, currículo e formação de professores. Santa Cruz do Sul: EDUNISC, 2004a. p. 19-38.

Currículo, cultura e saberes na educação matemática de jovens e adultos: um estudo sobre a matemática oral camponesa. In: SEMINÁRIO DE PESQUISA EM EDUCAÇÃO DA REGIÃO SUL, 5., 2004, Curitiba. Anais... Curitiba: PUC-PR, 2004b.

Educação matemática, culturas e conhecimento na luta pela terra. Santa Cruz do Sul: EDUNISC, 2006a.

Regimes de verdade sobre a educação matemática de jovens e adultos do campo: um estudo introdutório. In: SEMINÁRIO INTERNACIONAL DE PESQUISA EM EDUCAÇÃO MATEMÁTICA, 3., 2006, Águas de Lindóia. Anais... Águas de Lindóia: Sociedade Brasileira de Educação Matemática, 2006b. .; WANDERER, Fernanda. "A vida deles é uma matemática": regimes de verdade sobre a educação matemática de adultos do campo. Revista Educação Unisinos, São Leopoldo, v. 4, n. 7, p. 56-61, jul./dez. 2006a.

Regimes de verdades sobre a educação matemática: um estudo da cultura camponesa do sul do país. In: SEMINÁRIO BRASILEIRO DE ESTUDOS CULTURAIS E EDUCAÇÃO, 2. 2006, Canoas. Anais... Canoas: Universidade Luterana do Brasil, $2006 \mathrm{~b}$.

MAURO, Suzeli. Uma história da matemática escolar desenvolvida por comunidades de origem alemã no Rio Grande do Sul no final do século XIX e início do século XX. Tese (Doutorado em Educação Matemática) - Programa de Pós-Graduação em Educação Matemática, Universidade Estadual Paulista, Rio Claro, 2005.

MONTEIRO, Alexandrina. A etnomatemática em cenários de escolarização: alguns elementos de reflexão. In: KNIJNIK, Gelsa; WANDERER, Fernanda; OLIVEIRA, Cláudio José. Etnomatemática, currículo e formação de professores. Santa Cruz do Sul: EDUNISC, 2004. p. 432-446.

MORENO, Arley. Wittgenstein: os labirintos da linguagem. Ensaio introdutório. São Paulo: Moderna, 2000.

VEIGA-NETO, Alfredo. Foucault \& a educação. Belo Horizonte: Autêntica, 2003.
VILLELA, Denise Silva. Um estudo acerca da pluralidade das matemáticas. Projeto de Tese (Doutorado em Educação) - Faculdade de Educação, Universidade Estadual de Campinas, Campinas, 2006. WANDERER, Fernanda. Escola e matemática escolar: mecanismos de regulação sobre sujeitos escolares de uma localidade rural de colonização alemã do Rio Grande do Sul. Tese (Doutorado em Educação) - Programa de Pós-Graduação em Educação, Universidade do Vale do Rio dos Sinos, São Leopoldo, 2007.

WITTGENSTEIN, Ludwig. Investigações filosóficas. Petrópolis: Vozes, 2004.

FERNANDA WANDERER, doutora em educação pela Universidade do Vale do Rio dos Sinos (UNISINOS), é professora do Centro de Ciências Humanas na mesma instituição. Publicações recentes: “'A vida deles é uma matemática': regimes de verdade sobre a educação matemática de adultos do campo" (Educação Unisinos, v. 10, n. 1, p. 56-61, jan./abr. 2006); "Educação matemática e fruição da arte: uma análise da cultura dos azulejos portugueses em suas viagens nos tempos coloniais" (Horizonte, v. 22, n. 1, p. 17-28, jan./jun. 2005), ambos em co-autoria com KNIJNIK, Gelsa.E-mail: wanderer@unsinos.br

GELSA KNIJNIK, doutora em educação pela Universidade Federal do Rio Grande do Sul (UFRGS), é professora do Programa de Pós-Graduação em Educação da Universidade do Vale do Rio dos Sinos (UNISINOS), no qual coordena o grupo de pesquisa "Currículo, Cultura e Sociedade". Publicações recentes: Educação matemática, culturas e conhecimento na luta pela terra (Santa Cruz do Sul: EDUNISC, 2006); "Mathematics education and the Brazilian Landless Movement: three different mathematics in the context of the struggle for social justice" (Philosophy of Mathematics Education Journal, v. 21, n. 1, p. 1-18, set. 2007); e "Diversidad cultural, matemáticas y exclusión: oralidad y escrita en la educación matemática campesina del sur del Brasil" (In: GIMENEZ, Joaquín; DIEZ-PALOMAR, Javier (Orgs.). Educación matemática y exclusión. Barcelona: Graó, 2007. p. 63-82). Pesquisa em andamento: "Matemáticas e currículo escolar em cursos de pedagogia: um estudo etnomatemático”.E-mail: gelsak@unisinos.br

Recebido em outubro de 2007 Aprovado em janeiro de 2008 
emphasize that the interdisciplinarity movement can profoundly transform the quality of school education by means of its teaching processes.

Key words: interdisciplinarity; science; education; teaching-learning process; knowledge

\section{La interdisciplinariedad como un movimiento articulador en el proceso de enseñanza y aprendizaje}

Discute la interdisciplinariedad como un movimiento contemporáneo presente en las dimensiones de la epistemología y de la pedagogía, que viene marcando el rompimiento con una visión cartesiana y mecanicista de mundo y de educación y, al mismo tiempo asumiendo una concepción más integradora, dialéctica y totalizadora en la construcción del conocimiento y de la práctica pedagógica. Inicialmente, se hace una breve presentación del origen histórico de ese movimiento, se discuten aspectos de su conceptuación y sus implicaciones en el campo de las diferentes ciencias contemporáneas para entonces presentar la interdisciplinariedad como un importante fenómeno de articulación del proceso de enseñanza y aprendizaje. El argumento presentado en el texto busca destacar que el movimiento de la interdisciplinariedad puede transformar profundamente la calidad de la educación escolar por intermedio de sus procesos de enseñanza.

Palabras clave: interdisciplinariedad; ciencia; educación; proceso de enseñanza y aprendizaje; conocimiento

Fernanda Wanderer e Gelsa Knijnik

Discursos produzidos por colonos do sul do país sobre a matemática e a escola de seu tempo

$\mathrm{O}$ artigo apresenta resultados parciais de uma investigação que teve como propósito analisar discursos sobre a escola e a matemática escolar produzidos por um grupo de colonos, descendentes de alemães e evangélico-luteranos que freqüentavam uma escola rural do município de Estrela (RS), quando da efetivação dos decretos que instituíram a Campanha de Nacionalização - uma das medidas do Estado Novo (19371945), implementado no Brasil por Getúlio Vargas. A sustentação teórica do estudo encontra-se no campo da etnomatemática - constituído mediante os entrecruzamentos das teorizações pós-estruturalistas, em especial o pensamento de Michel Foucault, e das idéias formuladas por Ludwig Wittgenstein em sua obra Investigações filosóficas. O material de pesquisa examinado no artigo consiste em narrativas produzidas por sete colonos que estudaram naquela escola no período enfocado e em um texto elaborado por um dos participantes da pesquisa. $\mathrm{O}$ exercício analítico realizado mostrou que: a matemática escolar praticada naquela instituição foi sendo constituída como um conjunto de jogos de linguagem marcados pela escrita e pelo formalismo; as matemáticas geradas nas atividades cotidianas dos participantes do estudo podem ser significadas como conformando jogos de linguagem regidos por outra gramática, que utilizava regras como a oralidade, a decomposição, a estimativa e o arredondamento, constituindo critérios de racionalidade diferentes daqueles presentes nos jogos que engendravam a matemática escolar. Palavras-chave: matemática escolar; etnomatemática; teorizações pósestruturalistas

\section{Discourses produced by settlers} in the south of Brazil on the mathematics and school of their time The paper presents the partial results of research carried out with the aim of analysing the discourses on school and school mathematics of a group of German-descendant EvangelicalLutheran settlers who attended a rural school in Estrela (State of Rio Grande do Sul), at the time of the Nationalization Campaign - one of the actions taken by Getúlio Vargas during the Estado Novo (1937-1945) in Brazil. The theoretical framework of the study is the field of ethno-mathematics - shaped by poststructuralist theorizing, especially Michel Foucault's thinking, and the ideas of Ludwig Wittgenstein in his work Philosophical investigations. The data examined in the article consist of narratives produced by seven settlers who studied at the school during that period and a text written by one of the research participants. The analytical exercise carried out showed that: a) the school mathematics developed in that institution was instituted as a set of language games marked by writing and formalism; $b$ ) the mathematics generated by the settlers' everyday activities shaped language games constituted by another grammar, marked by rules such as orality, decomposition, estimations and rounding, which constitute rationality criteria that are different from those of the school mathematics language games.

Key words: school mathematics; ethno-mathematics; post-structuralist theorizing

Discursos producidos por colonos del sur del país sobre la matemática y la escuela de su tiempo

El artículo presenta resultados parciales de una investigación que tuvo como finalidad analizar discursos sobre la escuela y la matemática escolar producidos por un grupo de colonos, descendientes de alemanes y evangelistas luteranos que frecuentaban una escuela rural del municipio de Estrela (RS), cuando la efectividad de los decretos que establecieron la Campaña de Nacionalización - una de las medidas del Estado Nuevo (1937-1945), 
implementado en Brasil por Getúlio

Vargas. La sustentación teórica del estudio se encuentra en el campo de la etnomatemática - constituido mediante los entrecruzamientos de las teorías post estructuralistas, en especial el pensamiento de Michel Foucault, y de las ideas formuladas por Ludwig Wittgenstein en su obra Investigações filosóficas. El material de investigación examinado en el artículo consiste en narraciones producidas por siete colonos que estudiaron en aquella escuela en el período enfocado y en un texto elaborado por uno de los participantes de la pesquisa. El ejercicio analítico realizado, mostró que: la matemática escolar practicada en aquella institución fue siendo constituida como un conjunto de juegos de lenguaje marcados por la escritura y por el formalismo; las matemáticas generadas en las actividades cotidianas de los participantes del estudio, pueden ser significadas como ajustando juegos de lenguaje regidos por otra gramática, que utilizaba reglas como la oral, la desorganización, la estimativa y arredondando las cifras, constituyendo criterios de racionalidad diferentes de aquellos presentes en los juegos que engendraban la matemática local.

Palabras clave: matemática escolar; etnomatemática; teorías post estructuralistas

Maria Inês Petrucci Rosa e Tacita Ansanello Ramos

\section{Memórias e odores: experiências curriculares na formação docente Este artigo trata de memórias escolares de estudantes de licenciatura com- partilhadas na experiência do estágio,}

tendo como princípio de formação uma aproximação mais significativa com os fazeres do cotidiano escolar. Metodologicamente, a investigação questiona a clássica abordagem de produção de conhecimentos a partir do olhar, trazendo como elemento inovador a articulação entre a valorização de um caminho sensorial pouco usual - o olfato - e as memórias acionadas a partir dele. $\mathrm{Na}$ intenção de exercitar a possibilidade da escrita de histórias narrativas a partir de odores, foram propostas aos alunos as seguintes questões: que odores são sentidos no ambiente da escola onde se realiza seu estágio? Que memórias são acionadas a partir desses odores? Defendemos a idéia de que a formação docente passa também pelas memórias, muitas vezes inusitadas, pelas experiências comunicáveis e pelas sensibilidades dos professores em formação. Palavras-chave: formação docente; estágio supervisionado; memórias; narrativas; odores

\section{Memories and smells: curricular} experiences in teacher training This article deals with the shared school memories of undergraduate students during placement experience, promoting a more meaningful approximation with the daily life of the school as a principle of teacher training. Methodologically the investigation questions the conventional approach to the production of knowledge based on looking, and introduces as the innovative element the link between the promotion of that unusual sensory path - the smell and the memories triggered by it. The following questions were put to the students with the intention of exercising the possibility of writing stories based on these smells: what smells were perceived in the school environment where you did your placement? What memories were triggered by these odours? We defend the idea that teacher training is also transmitted by the often unusual memories, communicated by the experiences and the sensibilities of the teachers in training.

Key words: teacher training; supervised placement; memories; narratives; smells

Memorias y olores: experiencias curriculares en la formación docente

Este artículo trata de memorias escolares de estudiantes de licenciatura compartidas en la experiencia de la práctica, teniendo como principio de formación una aproximación más significativa con los hechos del cotidiano escolar. Metodológicamente, la investigación cuestiona la clásica abordaje de producción de conocimientos a partir de la mirada, trayendo como elemento innovador la articulación entre la valorización de un camino sensorial poco común - el olfato - y las memorias accionadas a partir de él. Con la intención de ejercitar la posibilidad de escribir historias narrativas a partir de olores, fueron propuestas a los alumnos las siguientes cuestiones: ¿qué olores son sentidos en el ambiente de la escuela donde se realiza su práctica? ¿Qué memorias son accionadas a partir de esos olores? Defendemos la idea de que la formación docente pasa también por las memorias, muchas veces inusitadas, por las experiencias comunicables y por las sensibilidades de los profesores en formación.

Palabras clave: formación docente; práctica supervisionada; memorias narrativas; olores 